\title{
OS POSITIVISMOS NO BRASIL DA VIRADA DO SÉCULO XIX PARA O XX: QUANDO A POLÍTICA E A LITERATURA SE MESCLAM
}

\author{
Isabela Melim Borges ${ }^{81}$
}

Resumo: Este artigo tem o intuito de refletir sobre o Positivismo e filosofias adjacentes, durante a implantação da primeira República, focalizando as ideias dos literatos durante a virada do século XIX para o $\mathrm{XX}$. Para tentar compreender a influência e as consequências daquela filosofia, fez-se um apanhado rápido das doutrinas que imperavam no Brasil antes de as novas ideias chegarem. Também abordou-se um dos tópicos mais essenciais da doutrina de Auguste Comte: a subordinação do subjetivismo ao objetivismo, que foi tratado pontualmente nas principais ideias de Silvio Romero e de José Veríssimo, tanto nas suas visões sociais e políticas como nos seus entendimentos acerca da poesia brasileira.

Palavras-chave: Positivismo; ideias; literatura; poesia brasileira.

Abstract: This paper aims to reflect on Positivism and adjacent philosophies during the implementation of the first Republic, focusing on the ideas of the literati during the turn of the nineteenth century to the twentieth. In order to try to understand the influence and consequences of that philosophy, a quick survey was made of the doctrines that prevailed in Brazil before the new ideas arrived. One of the most essential topics of Auguste Comte's doctrine was also discussed: the subordination of subjectivism to objectivism, which was dealt with punctually in the main ideas of Silvio Romero and José Veríssimo, both in their social and political views and in their understandings of Brazilian poetry.

Keywords: Positivism; ideas; literature; Brazilian poetry.

${ }^{81}$ Doutoranda de Literatura Brasileira pelo programa de pós-graduação da Universidade Federal de Santa Catarina - UFSC. 


\section{Introdução}

Este artigo é parte de um trabalho de pesquisa cujo tema principal trata das influências positivistas e de seus desdobramentos na poesia brasileira durante a virada do século XIX para o XX. Porém, o que proponho neste texto é um pequeno panorama do contexto social e político por qual o Brasil passava quando as ideias positivistas juntamente com outras - adentraram no país. Também pretendo abordar aqui como essas ideias chegaram, quais os principais intelectuais que tiveram os primeiros contatos com elas e que tipo de reações desencadearam. Para começar, escolhi Silvio Romero e José Veríssimo, por conta, obviamente, do grande prestígio e notoriedade de ambos, enquanto pensavam o país e a intelectualidade daquela época. É também relevante indicar quais correntes influíram na vida intelectual do Brasil e que estiveram implicadas, de algum modo, na experiência histórica e, consequentemente literária, pela qual o nosso país passava naquele momento. Dessas influências e dessa experiência, resultou um estilo de vida que nos parece próprio. De acordo com Cruz Costa, na introdução do Panorama da história da filosofia no Brasil, "este nacional é o que estaria na base da reinterpretação que fazemos dos modelos europeus e o que impediria uma total identificação nossa com o sentido da problemática do pensamento europeu que nos foi e ainda é transmitido" (1960). Assim, desse processo de reinterpretação, resulta uma deformação - $a$ priori nem boa nem má, nem correta nem equivocada - que pode até acabar se traduzindo em certa originalidade, claramente distinta de sua matriz europeia. No caso, cabe a indagação: considerando as implicações disso, seria possível contradizer a ideia de que, no Brasil, haveria mais tradução do que tradição, mesmo que a maioria dos comentadores brasileiros alegue que grande parte do que foi dito e escrito, em termos de ideias, foi apenas traduzido (seja do francês, alemão ou inglês)?

\section{Contexto social e político}

A segunda metade do século XIX é tida como um dos períodos de maior transformação da história brasileira. Um dos momentos-chave desta época é, como bem trata Hélio Silva em a História da República Brasileira 1888-1894, o despertar da consciência republicana, que se dá por volta do ano de 1870 , fase marcada também pelo término da Guerra 
Os positivismos no Brasil da virada do século XIX para o XX: quando a política e a literatura se mesclam | 281 do Paraguai ${ }^{82}$ - momento em que o Brasil começa a se enxergar como uma nação - e pelo lançamento do Manifesto Republicano, que, de acordo com Silva, não causou o impacto esperado por faltar-lhe "vibração e originalidade", por não se aprofundar nos problemas brasileiros, como a questão da escravatura, por exemplo (1998, p. 43). No entanto, sabemos que os fatos históricos não são estanques: quando me refiro ao despertar de uma consciência republicana, logicamente penso em um emaranhado de outros importantes acontecimentos, principalmente na significativa participação dos positivistas durante e após a implantação da República. De acordo com Ivan Lins, a República só se proclamou "graças à direção impressa ao movimento revolucionário por Benjamin Constant ${ }^{83 "}$ (1964, p. 303), que tinha liderança moral e intelectual adquiridas em todo o país e entre os importantes oficiais da época.

O Catolicismo é outro elemento que participa do debate e, mesmo a contrapelo, da implantação das ideias positivistas, segundo Silvio Romero no prefácio às Explicações Indispensáveis de Tobias Barreto (1900 p. 23). Segundo Romero, até 1868 nenhuma oposição se apresentou à principal corrente de pensamento que recebemos da herança portuguesa: a religião católica. Esta sempre foi "menos atenta ao sentido íntimo das cerimônias do que ao colorido e à pompa exterior", como escreve Sérgio

82 "A Guerra do Paraguai, que silenciara por algum tempo o problema da escravidão, pôs em relevo as debilidades orgânicas de um país em que a massa da população era constituída de escravos. O Brasil, embora vitorioso, saía da guerra humilhado, não somente em face de seus aliados, mas dos próprios vencidos, com suas tropas de libertos recém-egressos da escravidão. A questão da abolição do regime servil se tornará daí por diante um ponto de honra nacional. A monarquia sentiu no movimento abolicionista o sinal do seu fim" (COSTA, 1967, p. 119).

${ }^{83}$ Benjamin Constant Botelho de Magalhães entrou para o Exército, transferindose para a Escola Militar, onde terminou os estudos. Foi professor concursado do colégio Pedro II, sofreu profunda influência positivista, passando a difundir essas ideias na Escola Militar. Seduzido principalmente pelas implicações políticas do pensamento de Comte, passou a considerar o exército como o grupo social mais qualificado no país, responsável, portanto, pela transformação republicana no Estado brasileiro. Dessa forma, fica claro que depois da Monarquia, nossa primeira República foi militar, da qual faziam parte: Dr. Aristides Lobo (ministro do interior), tenente coronel Dr. Benjamin Constant (ministro da guerra), Dr. Ruy Barbosa (ministro da fazenda), marechal Deodoro da Fonseca (chefe do governo provisório), Quintino Bocaiúva (ministro das relações exteriores), Dr. Campos Salles (ministro da justiça), Eduardo Wandenkolk (ministro da marinha), Dr. Demétrio Ribeiro (ministro da agricultura); todos maçons. 
Buarque de Holanda (Raizes do Brasil, p. 108) e, por certo, menos atenta ainda à espiritualidade e à doutrina. De fato, o Catolicismo nunca teve uma influência decisiva na classe dirigente do Império, que era racionalista e cética. Silvio Romero admite ainda que é a partir da segunda metade do século XIX que se dão as maiores comoções da alma nacional, com respeito a ele

até então nada fora verdadeiramente examinado e criticado: o catolicismo não sofrera abalo; a filosofia católica acomodara-se ao ecletismo, o império não sofrera críticas sérias e, sobretudo, a instituição servil e os direitos tradicionais do feudalismo prático dos grandes proprietários, a mais indireta opugnação, o romantismo, com os seus doces, enganosos e encantadores cismares, a mais apagada desavença reatora. [...] E é então que, por um movimento subterrâneo, que vinha de longe, a instabilidade de todas as coisas se mostrou (prefácio de Explicações Indispensáveis, p 87-88).

O historiador chama atenção para a ausência de uma análise profunda que atingisse toda a instituição econômica, política e literária do segundo Império, baseada no servilismo (político, inclusive!) e que tinha como "filosofia" principal o Catolicismo. Mas não era apenas este que se fazia presente, havia um complexo aglomerado de outras filosofias importadas, tais como os distintos ecletismos que aqui se propunham, ademais do Enciclopedismo e até mesmo da Escolástica ${ }^{84}$. De fato, o Catolicismo era, na prática, a doutrina dominante nesse tempo e, tal qual na Europa, o clero brasileiro estava também em crise, o que, evidentemente, favorecia a emergência de novas filosofias:

O movimento de ideias que antes de acabada a primeira metade do século XIX se começara a operar na Europa com o Positivismo comtista, o transformismo darwinista, o Evolucionismo spenceriano, o intelectualismo de Taine e Renan, e que se fazia sentir vinte anos depois de haverem estas correntes de ideias aparecido na Europa, espalhara-se pelo país todo (COSTA, 1967, p. 122).

${ }^{84}$ Em Cruz Costa, 1967, p. 101. 
Os positivismos no Brasil da virada do século XIX para o XX: quando a política e a literatura se mesclam | 283

Ocorria aqui, assim, um surto de ideias revolucionárias num país que tinha se tornado independente há apenas 40 anos. Uma das causas está no progresso material que, por volta de 1860 , começa a apontar no horizonte brasileiro, quando se dá uma inversão no movimento dos capitais: antes empregados no tráfico negreiro, são agora utilizados no comércio e num embrião industrial. Também o que acontecia no estrangeiro reforçava esse processo, de certa forma, como ocorreu com a proclamação da terceira república da França em 1871. Fatos como esse, somados a suas consequências, repercutiam quase que de forma imediata no Brasil. De acordo com Cruz Costa, O Manifesto Republicano e o germanismo da Escola do Recife são também frutos desses movimentos.

Graças à divulgação das novas ideias sobre filosofia e literatura, formou-se no Brasil, no decênio de Setenta, uma geração de tendências eminentemente críticas, animada no desejo de esquadrinhar a cultura nacional e dar-lhe orientação diversa. Um verdadeiro modernismo, como apelidou José Veríssimo, cujo foco principal foi a capital de Pernambuco. [...] Parece fora de dúvida que a divulgação do Positivismo, do Evolucionismo e da crítica moderna no Brasil se processou, senão a princípio, pelo menos mais intensamente no Recife. Os primeiros sinais em que encontramos sinais da nova crítica são os de Sílvio Romero, Celso de Magalhães, Rocha Lima, Capistrano de Abreu e Araripe Júnior, os últimos três pertencendo ao grupo que se formou no Ceará, mas tendo os seus componentes estudado antes naquela cidade (CANDIDO, 1988, p. 32).

Antonio Candido confirma a efervescência das novas ideias, além de situar o início do debate através da escola do Recife. Esta se tornou produtora e difusora de um pensamento social calcado em concepções teóricas/filosóficas que mesclavam o Positivismo com o Evolucionismo determinista do darwinismo social e que tinha nas questões da raça e da miscigenação o foco de suas formulações doutrinárias. A Escola do Recife, sem dúvida, teve papel de destaque na constituição de interpretações sobre o Brasil que ampararam a visão de mundo das elites dirigentes e deram suporte teórico aos projetos de construção de uma nação civilizada. Entre os intelectuais empenhados em introduzir a razão científica, o Positivismo e o Evolucionismo darwinista na produção do 


\section{4 | Isabela Melim Borges}

pensamento social, estavam Tobias Barreto e Sílvio Romero, intelectuais que participaram da vanguarda do que ficou conhecida como Geração de 1870. Dela também faziam parte Aníbal Falcão, Franklin Távora, Araripe Jr., Clóvis Bevilácqua, Higino Cunha, Graça Aranha, Artur Orlando e Martins Jr. Esses literatos, abolicionistas e republicanos que eram, partindo de um distanciamento crítico da monarquia escravocrata, defenderam a laicização da sociedade brasileira, além de combaterem o ideário romântico que, no último quartel do século XIX, ainda tentava ditar arquétipos para formar uma identidade nacional.

Outro ponto de extrema importância na construção da já citada consciência republicana era a escravidão africana que não havia sido encarada em termos verdadeiramente capitalistas, tampouco humanistas. Era necessário o seu fim, principalmente para se encaixar nos ideais positivistas: Auguste Comte alicerçava-se na ideia de que a sociedade só poderia ser organizada de forma positiva ${ }^{85}$, após uma completa reforma intelectual do homem. Para o filósofo, as ideias transformam as condições sociais, econômicas e políticas e não o contrário. Consequentemente, é com o advento das ideias positivistas que se começa a vislumbrar tanto a abolição da escravidão como a formação de uma república. É natural que, num contexto como o que se expôs, em um país que possuía como doutrina preponderante o Catolicismo misturado a um aglomerado de ideias fragmentárias como as já citadas anteriormente, juntamente com um modo de exercício do poder bem definido (isto é, um regime aristocrático baseado no regime servil), é natural que se aspirasse a utilizar as novas ideias que então começavam a chegar, para criticar essas relações de poder. Ora, tratava-se, de fato, de uma miríade de ideias que, ao contrário, apontavam justamente para a alteração do status quo, para a modernização da sociedade e para a atualização do sistema produtivo. $\mathrm{O}$ Positivismo, o Naturalismo, o Evolucionismo, o Liberalismo chegavam ao Brasil ligados à luta por modificações estruturais. De acordo com Joaquim Nabuco, "até então, o espírito comercial e industrial do país resumia-se na importação e venda de africanos. Com a extinção, deu-se uma transformação maravilhosa. Este fato teve um imenso alcance, mudando completamente a face de todas as coisas... (Apud COSTA, p. 40). Joaquim

\footnotetext{
${ }^{85} \mathrm{O}$ espírito positivo está afastado do empirismo e do misticismo, caminha entre eles. O estado Positivo precisa de uma Observação Verdadeira: única base de conhecimentos verdadeiramente acessíveis, criteriosamente adaptados às nossas necessidades reais; e de uma Busca às Leis das relações que existem entre os fenômenos observados.
} 
Os positivismos no Brasil da virada do século XIX para o XX: quando a política e a literatura se mesclam | 285

Nabuco foi um personagem também importante, pois, abolicionista e monarquista que era, ajudou os setores mais conservadores a perceberem que a escravidão no Brasil era uma mácula para o Estado e uma ineficiência para a economia e que, sem atuação do próprio Estado no sentido de propiciar a abolição, seria muito difícil pôr fim a ela. Era uma concepção minimamente próxima ao republicanismo positivista, que oferecia uma saída, embora este começasse pela condenação da Monarquia em nome do progresso, pela separação entre Igreja e Estado, por uma ditadura republicana com um Executivo forte e intervencionista e pela proposta de incorporação do proletariado à sociedade moderna. $\mathrm{O}$ grupo que mais se interessou por esses ideais foram os militares. Também vale destacar aqui o que José Murilo de Carvalho afirma quanto à questão militar:

O fato é extremamente irônico, de vez que, de acordo com as teses positivistas, um governo militar seria uma retrogradação social. Mas entram aí as surpresas que fazem interessante o fenômeno da adaptação de ideias. Acontece que os militares tinham formação técnica, em oposição à formação literária da elite civil e sentiam-se fortemente atraídos pela ênfase da pelo Positivismo à ciência, ao desenvolvimento industrial. Por outro lado, por serem parte do próprio Estado, não podiam dele prescindir como instrumento de ação política (1990, p. 27-28).

O historiador admite que um governo militar seria um retrocesso segundo as regras da doutrina positivista, no entanto esta teve que se adaptar ao clima tropical para aqui proliferar; também Cruz Costa fala que houve, assim, uma reinterpretação das ideias filosóficas, fato que, mantidas as devidas distâncias, não deixa de ser um certo movimento antropofágico $^{86}$ nas ideias.

${ }^{86}$ O Manifesto Antropofágico propunha basicamente 'devorar' a cultura e as técnicas importadas e provocar sua reelaboração com autonomia, transformando o produto importado em exportável. Buscava a importação de novidades europeias, com objetivo de movimentar o pensamento, depois, antropofagicamente, isto é, criticamente, devorar estas novidades e influências à medida que os modernistas redescobrem a realidade brasileira. 


\section{Quando as ideias começaram a jorrar}

Nas fontes pesquisadas, não há um consenso sobre uma data específica do aparecimento do Positivismo no Brasil. Ivan Lins traz a informação de que o Visconde de Taunay teve um professor de matemática, Antônio Machado Dias, no Colégio Pedro II, em 1855, que era um discípulo direto de Auguste Comte. Clóvis Bevilácqua acredita que foi em 1858. Cruz Costa admite que o Positivismo apareceu, primeiramente, no norte do país, em 1868, em conferência que Tobias Barreto fez acerca das ideias de Augusto Comte. Hélio Silva diz que foi em 1871, por meio do discurso de Benjamin Constant realizado no Palácio dos Cegos. Há também indícios de que o marco inaugural da difusão do Positivismo, em caráter especulativo, teria sido a obra de Luís Pereira Barreto, As Três Filosofias (considerada como a primeira obra de divulgação da doutrina positivista no Brasil), cujo primeiro volume foi publicado em $1874^{87}$. Por conseguinte, foi no Colégio Pedro II, na Escola Militar e na Escola Politécnica que os preceitos da doutrina de Comte começaram realmente a ter uma maior visibilidade e crescente número de seguidores (mesmo que tal militarização evidencie um retrocesso político e esteja em desacordo com os ideais positivistas, como já falado logo acima).

Não posso deixar de salientar que o Positivismo entrou no Brasil de modo bipartido: existiam os positivistas heterodoxos, seguidores de Émile Littré; e os positivistas ortodoxos, de Pierre Laffitte. Tanto um quanto o outro foram apóstolos de Comte, porém, em determinada etapa do percurso filosófico, quando os elementos religiosos predominam sobre os aspectos científicos (o pressuposto é basicamente este, mas, é evidente que estou aqui simplificando), ou seja, o primeiro rumou para o lado científico; o segundo, para o religioso - em defesa da religião da Humanidade. É a partir dessas duas perspectivas que são apresentadas, a seguir, as visões de Silvio Romero e de José Veríssimo, a partir do que

${ }^{87}$ De acordo com Ivan Lins, a partir de 1837, vários brasileiros seguiam, na Escola Politécnica de Paris, os cursos de Auguste Comte, entre eles estão J. O. de Almeida, Patrício de Almeida e Silva, Agostinho Roiz Cunha, Antônio Campos Belos e Antônio Machado Dias - este mais tarde seria professor de matemática do Colégio Pedro II - e Felipe Ferreira de Araújo Pinho. É, porém, de 1844, a primeira referência à obra de Comte, no Brasil. Na tese sustentada pelo Dr. Justiniano da Silva Gomes - Plano e Método de um Curso de Filosofia - referiase ele a Comte, ao método positivo e à lei dos três estados (LINS, 1964, p. 12-18). 
Os positivismos no Brasil da virada do século XIX para o XX: quando a política e a literatura se mesclam | 287

pensaram e formularam acerca das doutrinas filosófica da época e da literatura brasileira.

\section{De que forma se reflete sobre essas ideias a partir de nossa literatura?}

Durante esse mesmo período acima esboçado, a transformação no campo das ideias tinha como alvo questionar e acabar com o Romantismo como movimento estético e também preconizar o declínio da Metafísica. Não havia mais lugar para o espírito e tudo estava sob o jugo da razão. Para a filosofia Comtista, no mundo moderno racional-positivista não havia mais lugar para a subjetividade que o Romantismo ditou. No prefácio do seu Catecismo positivista, Auguste Comte inspirou uma receita que parcela importante da arte e do pensamento ocidental de finais do século XIX aproveitariam para tentar enterrar toda subjetividade que ainda imperava. Para o filósofo, "a nossa verdadeira liberdade resulta essencialmente de uma digna submissão” (1988, p. 144), além de admitir também que o elemento subjetivo deve estar sempre subordinado ao objetivo, sendo esta uma verdade essencial; assim, funda-se uma estrutura na qual o elemento subjetivo não é aniquilado, mas posto em seu lugar “positivo" (1988, p. 144). Nos diz Comte: "A principal força de nossa razão consiste [...] em subordinar suficientemente o subjetivo ao objetivo, para que nossas operações interiores possam representar o mundo exterior com o predomínio imutável que a este pertence" (idem). De acordo com Sérgio Alves Peixoto, a poesia inerente a este momento literário seria

Uma poesia na qual o subjetivismo deve residir dentro do poeta e ser subordinado à razão que, clara e objetivamente, deve ver o mundo como ele é. Subjetivismo sim, mas observado atentamente pela razão, a fim de não perverter a realidade e fantasiar-lhe o perfil. Disciplina, ordem, comedimento, eis alguns outros elementos da filosofia de Comte que permearão tanto a prosa quanto a poesia de certa literatura de finais do século (1999, p. 141).

No que diz respeito especificamente à produção literária que ocorreu durante a virada do século XIX para o XX, este artigo se limita a tentar entender como as ideias positivistas aqui entraram, como foram lidas e compreendidas pela intelectualidade daquele momento. 
Em sua obra Doutrina contra Doutrina (2001 [1894]), livro de sua segunda fase ${ }^{88}$, Romero ${ }^{89}$ elabora uma forte crítica ao Positivismo no Brasil, mesmo tendo sido adepto desta filosofia. Utilizando o Evolucionismo ${ }^{90}$ spenceriano como contraponto ao "atrasado Positivismo com seus anacronismos, ditaduras, seu patriarcado...” (Ibid.: 122), Romero defende que o Brasil é "fatalmente democrático" (Ibid.: 72). Em outras palavras, para ele, a nação brasileira surge no momento posterior ao fim das aristocracias próprias do Antigo Regime quando a mestiçagem funcionou como um mecanismo que tornou a sociedade brasileira naturalmente igualitária e onde o governo aristocrático e autoritário de poucos não condiria com os fatores do meio social brasileiro. Esse processo de afastamento em relação ao Positivismo e a sua adesão irrestrita ao Evolucionismo de Herbert Spencer atinge o auge na trajetória de Romero no início do período republicano e revela que uma de suas motivações foi o cenário político conturbado da república brasileira nos seus primeiros anos. É neste instante que Silvio Romero, de acordo com Antonio Candido, prima por suas convicções e paixões partidárias (1988, p. 79). Para Romero, "o Positivismo teria tomado forma no Brasil como uma seita, um emaranhado de fanáticos, servindo ao sectarismo dos militares e às configurações oligárquicas regionais" (Ibid.: 116). Dessa maneira, para Romero, que não estava de acordo com o rumo doutrinário positivista, a questão não era apenas uma mera disputa de ideias, mas tinha importância porque implicava questões práticas da vida política e social do país. Para o autor, o combate aos desmandos do militarismo no período republicano e à crítica ao autoritarismo e ao regionalismo oligárquico passavam majoritariamente pela crítica ao suporte filosófico que os sustentava: o Positivismo. Segundo ele:

${ }^{88}$ De acordo com Antonio Candido, a segunda fase de Silvio Romero significa uma depuração do Evolucionismo spenceriano, com liquidação geral do Positivismo e restrições severas a Haeckel; passagem gradual da filosofia para a sociologia (1988, p. 80$)$.

${ }^{89}$ Quando, na Escola do Recife, Silvio Romero era sim Positivista.

${ }^{90}$ Evolucionismo de Spencer que, de acordo com Nicola Abbagnano, não deixa de ser um tipo de Positivismo: "É possivel distinguir duas formas históricas fundamentais do Positivismo: o Positivismo social de Saint-Simon, Comte e John Stuart Mill, nascido da exigência de construir a ciência como fundamento de um nova ordenação social e religiosa unitária; e o Positivismo evolucionista de Spencer, que estende a todo o universo o conceito de progresso e procura impô-lo a todos os ramos da ciência" ( Dicionário de Filosofia, 2007, p. 909). 
Os positivismos no Brasil da virada do século XIX para o XX: quando a política e a literatura se mesclam | 289 A república do Positivismo tem de república apenas o nome: está para o verdadeiro ideal republicano como o governo autocrático do Czar está, na ordem da realeza, para a monarquia constitucional da Inglaterra. Nem mais, nem menos. É o que é fácil de verificar, chamando a depor as bases de uma constituição política ditatorial federativa para a República brasileira, publicadas pelo apostolado central.

Toda essa aversão ao Positivismo, enquanto doutrina social, destoa bastante dos seus escritos anteriores, tal qual o ensaio A poesia de hoje:

No meio das mutações por que hão passado todos os ramos do pensamento humano, qual será o estado a que se deve ter chegado a poesia? Qual o seu caráter de hoje? Esta pergunta não é nova, nem tem sido uma só a resposta a ela dada. [...] $\mathrm{O}$ poeta deve ter as grandes ideias que a ciência de hoje certifica em suas eminências; não para ensinar geografia ou linguística, pré-história ou matemática; mas para elevar o belo com os lampejos da verdade, para ter a certeza dos problemas, além das miragens da ilusão... (1878).

Quando aborda a literatura, melhor dizendo, a poesia - gênero literário de maior ênfase no final do século XIX -, Silvio Romero se questiona, frente a tantas mudanças naquele pensamento intelectual, como se caracterizaria a poesia daquele momento. E conclui que, em decorrência das teorias científicas que estavam em voga, a poesia deveria "elevar o belo com os lampejos da verdade". Ora, uma vez que Romero admite "belo" e "verdade" na mesma frase, está assumindo a subordinação do subjetivo (belo) ao objetivo (verdade), tal qual aparece na doutrina comteana, o que futuramente será contestada e rebaixada pelo historiador na, entre outras, citada obra Doutrina contra doutrina. Assim, não só aqui neste excerto, mas em muitos outros, Silvio Romero se apropria do positivismo e o utiliza até mesmo em seus poemas científicos. Dessa forma, o crítico pode até não estar de acordo com o dogmatismo da filosofia positivista enquanto religião, porém, enquanto ciência e ideia nova, a absorveu em grande medida.

Outra personalidade de igual importância foi José Veríssimo. Em seu artigo "O Positivismo no Brasil" (publicado na Revista Brasileira, tomo 
IV, 1895), demonstra que essa doutrina exerceu forte influência na sua formação, defende seu valor e justifica seu prestígio. Nesse sentido, contra os ataques de Silvio Romero, advoga a necessidade de se distinguirem as marcas decorrentes da vulgarização e da deturpação que os princípios positivistas sofreram ao se propagarem no Brasil. Veríssimo estuda duas causas de sua disseminação: uma geral, comum a todos os povos, e outra local, peculiar ao nosso meio e a nossa evolução. $\mathrm{Na}$ ordem geral, ele julga que sua importância advém do fato de ser uma concepção filosófica capaz de ocupar o vazio deixado pela decadência da metafísica, pertencente a corrente literária do Romantismo, e do catolicismo como filosofia que, de forma geral, predominava no meio cultural e intelectual. Ele admite que o que distingue o Positivismo de todas as demais construções filosóficas é o fato de ser uma doutrina completa: uma filosofia, um dogma, uma política. E rebate Silvio Romero e seu pensamento evolucionista:

O evolucionista ou spencerista pode ser em política republicano ou monarquista, em religião pelo menos ateu ou deísta, em arte, idealista, realista, naturalista ou simbolista, em ciência, ficar em Darwin ou ir até Haeckel: pode ser pró ou contra o divórcio, favorável ou hostil ao livre câmbio, ao parlamentarismo ou presidencialismo, ao café, ao álcool, às comidas apimentadas. $O$ positivista, não: o mesmo dogma que the determina uma convicção científica, dá-lhe um critério moral ou artístico e regulamenta-lhe a família, a mesa, a atividade política, econômica e até sexual. É nisto justamente que está senão sua originalidade, a sua distinção e a sua força. Por isso os seus adeptos podem constituir-se em corporação, em igreja, e em virtude da lei da gravitação, verdadeira também no mundo moral, agir sobre as massas inconscientes e desorganizadas que a rodeiam (p. 302).

Dessa forma, face a tais argumentos, Veríssimo refuta a proposta de Silvio Romero que opõe o Evolucionismo ao Positivismo, no livro Doutrina Contra doutrina (1894). No que tange à poesia, José Veríssimo diz:

A poesia - como toda a forma de Arte - não é o que dela quer fazer um pensamento sutil, tentador, mas - e sinto estar em desacordo conosco - falso. A arte não é uma 
Os positivismos no Brasil da virada do século XIX para o XX: quando a política e a literatura se mesclam | 291 invenção pessoal. É o produto de uma emoção, sim, mas social e humana (...). Façamos, pois, (...) somente a Arte humana, a Arte de homens para homens, não a Arte de artistas para artistas, de estetas para estetas, arte egoísta e má, mas a Arte do mesmo profano vulgo compreendida. A Arte não é, não pode ser, um brinco e um divertimento, um simples passatempo de desocupados. Ela mereceria o desprezo dos que tais artistas chamam o burguês, se não fosse senão isso... (VERÍSSIMO, 1976, p. 132-133).

A observação de Veríssimo quanto à necessidade da poesia cantar o útil, o real, não está fora das questões que marcam a sociedade na virada do século XIX. Ele relaciona a poesia útil e real à sociedade burguesa e à construção da democracia. É nesse sentido que se opunha ao subjetivismo. $\mathrm{O}$ autor discute como os temas usuais dos poetas estavam ultrapassados, fazendo assim também uma crítica ao Romantismo. Toma, como exemplo, o amor que, a seu ver, não poderia mais ser poetizado apenas como uma afeição pessoal, sem influências externas, sociais e humanas. Faz referência aos grandes poetas do século XIX que tratam, sim, do amor, mas de forma universal. Cita, Goethe que chama de poeta universal, objetivo e social, e Byron, que, segundo ele, canta a revolta contra a sociedade. Para Veríssimo, os grandes poetas do século XIX são requeridos por outros temas, por diferentes posições e sentimentos. Quando esses grandes poetas se ocupam do amor sabem misturar-lhe elementos de consciência, dar-lhe a generalidade e complexidade que faz da pura paixão individual um interesse humano (VERÍSSIMO, 1977c, p. 92-93).

Portanto, era o espírito positivo, prático e materialista que colocava esses poetas na posição de exemplos a serem tomados. Para Veríssimo, à fadiga natural do amor juntava-se, o próprio espírito do nosso tempo, positivo, prático, materialista. Tal qual Silvio Romero, José Veríssimo dá validade à subordinação do subjetivismo ao objetivismo que Comte pregava, deixando patente a influência do Positivismo tanto na forma de ver o mundo quanto na de colocá-lo em palavras.

\section{Conclusão}

Este artigo teve como pretensão situar a doutrina Positivista, ou melhor, as principais ideias do Positivismo dentro da sociedade 
republicana brasileira em formação, a partir sobretudo do que dele disseram importantes literatos que lhe foram contemporâneos. O que fica claro é o quanto o Brasil intelectual-político-social da virada do século XIX para o XIX estava entranhado das novas filosofias e precisava delas para evoluir. O Positivismo é apenas uma das ideias que apareceram nesse período, talvez o país que mais absorveu essa filosofia tenha sido o Brasil. Afinal de contas, ela era uma das molas propulsoras que acelerou o processo evolutivo brasileiro, tanto no campo político, como no literário.

Faltou trazer para essa discussão a formação e desenvolvimento da Igreja Positivista do Brasil, com seu papel de destaque em nossa sociedade naquele período (isto durante e após a proclamação da República), cujas maiores expressões foram as de Miguel Lemos e as de Teixeira Mendes. Em trabalhos futuros, eles serão devidamente analisados.

Enfim, no que toca ao presente trabalho, a pretensão foi abrir para algumas discussões: como apreender o sentido dessa geração, composta por intelectuais tão díspares quanto Joaquim Nabuco, Benjamin Constant, Sílvio Romero, José Veríssimo, entre tantos outros, sobretudo no que diz respeito ao papel dos pensadores de nossa literatura? Como interpretar os textos de um conjunto de intelectuais e literatos que reúne liberais, republicanos, positivistas e federalistas, todos às voltas com Spencer, Comte e Darwin? O que se delineia no horizonte pode ser uma possível resposta à pergunta feita na introdução deste texto: nem tradução, tampouco tradição, talvez uma reinterpretação de filosofias estrangeiras, algo como uma antropofagia ideológica (como já falado aqui em algum lugar!), cujo critério parece ter sido político.

\section{REFERÊNCIAS}

ABBAGNANO, Nicola. Dicionário de filosofia, tradução coordenada e revista de Alfredo Bosi. São Paulo: Martins Fontes, 2007.

BEVILACQUA, Clovis. Esboços e Fragmentos. In: <https://www.literaturabrasileira.ufsc.br/documentos/?action=downl oad\&id=44069>. Acesso em: 15/02/2018.

CANDIDO, Antonio. O método crítico de Silvio Romero. São Paulo: Editora USP, 1988.

CARVAlHO, José Murilo de. A formação das almas: o imaginário da república no Brasil. São Paulo: Companhia das Letras, 1990.

COMTE, Auguste. Curso de filosofia positivista; Discurso sobre o espírito 
Os positivismos no Brasil da virada do século XIX para o XX: quando a política e a literatura se mesclam | 293 positivo; Catecismo positivista. São Paulo: Ed. Abril. 1988.

COSTA, Cruz. Panorama da história da filosofia no Brasil. São Paulo: Cultrix, 1960.

. Contribuição à história das ideias no Brasil. Rio de Janeiro: Editora Civilização Brasileira, 1967.

HOLANDA, Sérgio Buarque. Raizes do Brasil. São Paulo: Companhia das Letras, 2006.

LINS, Ivan. História do positivismo no Brasil. São Paulo: Companhia editorial nacional, 1964.

PEIXOTO, Sérgio Alves. A consciência criadora na poesia brasileira: do barroco ao simbolismo. São Paulo: Annablume, 1999.

ROMERO, Silvio. Introdução a Doutrina contra doutrina. São Paulo: Companhia das letras, 2001.

SILVA, Hélio. História da república brasileira. São Paulo: Editora Três Ltda, 1998.

VERÍSSIMO, José. Estudos de literatura brasileira - primeira série. Belo Horizonte: Itatiaia; São Paulo: EDUSP, 1976.

. Estudos de literatura brasileira - quinta série. Belo Horizonte: Itatiaia; São Paulo: EDUSP, 1977c.

Recebido em: 15/02/2018

Aceito em: 20/03/2018 